\title{
Depressive symptoms and dietary non- adherence among end stage renal disease patients undergoing hemodialysis therapy: systematic review
}

\author{
Mignote Hailu Gebrie ${ }^{1 *}$ (D) and Jodi Ford ${ }^{2}$
}

\begin{abstract}
Background: Research suggests that patients with end stage renal disease undergoing hemodialysis have a higher rate of depression and dietary non adherence leading to hospitalization and mortality. The purpose of this review was to synthesize the quantitative evidence on the relationship between depressive symptoms and dietary non adherence among end stage renal disease (ESRD) patients receiving hemodialysis.

Methods: A systematic review was undertaken. Three electronic databases were searched including PubMed, CINHAL and Web of Science. Only quantitative studies published between 2001 and 2016 were included in the review.

Result: A total of 141 publications were reviewed during the search process and 28 articles that fulfilled the inclusion criteria were included in the review. Eleven studies (39.3\%) reported on the prevalence of depressive symptoms or depression and its effect on patient outcomes. Ten studies (35.7\%) focused on dietary adherence/non adherence in patients with ESRD and the remaining seven (25\%) articles were descriptive studies on the relationship between depressive symptoms and dietary non adherence in patients with ESRD receiving hemodialysis. The prevalence of depressive symptoms and dietary non adherence ranged as $6-83.49 \%$ and from $41.1-98.3 \%$ respectively. Decreased quality of life \& increased morbidity and mortality were positively associated with depressive symptoms. Other factors including urea, hemoglobin, creatinine and serum albumin had also association with depressive symptoms. Regarding dietary non adherence, age, social support, educational status, behavioral control and positive attitudes are important factors in ESRD patients receiving hemodialysis. Having depressive symptoms is more likely to increase dietary non adherence.

Conclusion: Depressive symptoms and dietary non adherence were highly prevalent in patients with end stage renal disease receiving hemodialysis therapy. Nearly all of the articles that examined the relationship between depressive symptoms and dietary non adherence found a significant association. Future research using experimental or longitudinal design and gold standard measures with established cut-points is needed to further explain the relationship.
\end{abstract}

Keywords: Depressive symptoms, Depression, Dietary adherence, Dietary non-adherence, End stage renal disease, Chronic renal disease, Nutritional status and hemodialysis

\footnotetext{
* Correspondence: elatman.hailu86@gmail.com

${ }^{1}$ University of Gondar, College of Medicine and Health Sciences, School of

Nursing, Gondar, Ethiopia

Full list of author information is available at the end of the article
}

(c) The Author(s). 2019 Open Access This article is distributed under the terms of the Creative Commons Attribution 4.0 International License (http://creativecommons.org/licenses/by/4.0/), which permits unrestricted use, distribution, and reproduction in any medium, provided you give appropriate credit to the original author(s) and the source, provide a link to the Creative Commons license, and indicate if changes were made. The Creative Commons Public Domain Dedication waiver (http://creativecommons.org/publicdomain/zero/1.0/) applies to the data made available in this article, unless otherwise stated. 


\section{Background}

End-stage renal disease (ESRD) is a growing public health problem with significant physiological, psychological and socio-economic implications for the individual, family and the community $[1,2]$. Despite advances in technology and medical care, it remains a serious and life-threatening illness with a very high mortality rate and low quality of life [3-5]. Studies revealed the world wide incidence and prevalence of ESRD is increasing and it is projected that by 2020 the number of patients with ESRD will rise by nearly $60 \%$ in comparison with that of 2005 [6, 7].

There are three treatment modalities for ESRD including hemodialysis, peritoneal dialysis, and transplant. Particularly, hemodialysis, one of the most extensively used renal replacement for patients with the disease [8-11] imposes a great psychosocial burden on the patients due to the number of lifestyle, dietary, and fluid restrictions required to manage their disease $[1,2]$.. However, evidence indicates that patients are frequently non adherent with prescribed medications and dietary and fluid recommendations causing ongoing challenges in the care of these patients [1]. Moreover, these restrictions can impact a patient's sense of personal control that can lead to disruptions in social relations and social withdrawal resulting in depression [2, 12-14].

In patients with ESRD, adherence to dietary restrictions is significantly associated with improved patients' outcomes while non adherence has a risk of complication leading to death [15]. A study identified and grouped factors contributing to non-adherence as patient related, psychological, disease related, socioeconomic, therapy related and health care system related factors with their sub factors [1]. For example, in one study satisfaction with social support, comorbidity and monthly family income were factors found to be associated with dietary and fluid adherence [16]. However, others have reported discrepancies of results in studies that assessed the predictors of dietary non adherence in patients with ESRD receiving hemodialysis due primarily to the lack of a standardized method by the researchers for measuring non adherence [17].

Extant research has found that depression is the most common mental comorbidity among ESRD patients [12, 18, 19], although prevalence rates vary widely across studies ranging from 20\% [20] to $90 \%$ [21]. Depressive symptoms also have been found to be associated with low adherence to prescribed dialysis treatments, including dietetic recommendations that may result in increased morbidity and mortality [2]. Despite these findings, depression remains underdiagnosed and understudied in ESRD patients [4, 22]. Depressive symptoms play a significant role in causing malnutrition that is closely related with morbidity, mortality, decrease in quality of life and delayed recovery in ESRD patients [22]. However, studies have demonstrated inconsistent findings about the relationship between depressive symptoms and fluid and dietary adherence in patients with ESRD [1]. In some studies, a negative relationship was established while in others no significant relationship was found. Therefore, the purpose of this paper is to review the prevalence of depressive symptoms and dietary non adherence in ESRD patients receiving hemodialysis and to provide a review of the quantitative research evidence regarding the relationship between depressive symptoms and dietary non adherence inpatients with ESRD receiving hemodialysis.

\section{Methods}

\section{Search strategy}

A systematic review was conducted to synthesize the different literatures regarding depressive symptoms and dietary non adherence in patients with ESRD who were receiving hemodialysis therapy. Three databases, CINAHL, PubMed and Web of Science were consulted using key words that included, "depressive symptoms", depression, "dietary adherence/non adherence", ESRD, "end stage renal disease", "end stage kidney disease", "end stage renal failure", "nutritional status", "dietary compliance/noncompliance" and hemodialysis. Boolean operators like "AND" and "OR" were used to combine search terms. We used MeSH terms for entry term suggestion. Bibliographies of relevant articles were also retrieved using hand searches. Search results were limited to English language articles published between 2001 and 2017, resulting in 141 articles, consisting of studies identified by electronic database search as $n=128$ and articles identified from other searches as $n=13$. Articles were screened for duplication and duplicates were removed $n=29$. After removal of duplicated data, articles abstracts were screened for eligibility, which resulted in the elimination of 79 articles that were non English, studies in abstract form, studies done before 2000, comments or editorials. Finally, further screening of articles was done with application of the inclusion and exclusion criteria and critical appraisal was done by the Joanna Briggs Institute (JBI) check list (Table 1) by both authors and 28 articles that met these criteria were included in the review (Fig. 1).

\section{Inclusion and exclusion criteria}

This review included studies that were: - (1) written in English; (2) quantitative study design; (3) adults (aged 18 years or older) who were receiving hemodialysis for at least 3 months; and (4) published between 2001 and 2016. For the purpose of this review, studies that met these criteria were then categorized by types of study 
Table 1 Joanna Briggs Institute critical appraisal checklist for analytical cross sectional studies

\begin{tabular}{|c|c|c|c|c|c|}
\hline Sr.no & Critical appraisal checklist & Yes & No & Unclear & Not applicable \\
\hline 1 & $\begin{array}{l}\text { Were the criteria for inclusion in the sample } \\
\text { clearly defined? }\end{array}$ & $\sqrt{ }(28)$ & & & \\
\hline 2 & $\begin{array}{l}\text { Were the study subject and the setting } \\
\text { described in detail? }\end{array}$ & $\sqrt{ }(28)$ & & & \\
\hline 3 & $\begin{array}{l}\text { Was the exposure measure in valid and } \\
\text { reliable way? }\end{array}$ & $\sqrt{ }(25)$ & $\sqrt{ }(3)$ & & \\
\hline 4 & $\begin{array}{l}\text { Were objective, standard criteria used for } \\
\text { measurement of the condition? }\end{array}$ & $\sqrt{ }(28)$ & & & \\
\hline 5 & Were confounding factors identified? & $\sqrt{ }(12)$ & & $\sqrt{ }(16)$ & \\
\hline 6 & $\begin{array}{l}\text { Were strategies to deal with confounding } \\
\text { factor stated? }\end{array}$ & $\sqrt{ }(7)$ & & $\sqrt{ }(19)$ & \\
\hline 7 & $\begin{array}{l}\text { Was the outcome measured in a valid and } \\
\text { reliable way? }\end{array}$ & $\sqrt{ }(23)$ & & $\sqrt{ }(5)$ & \\
\hline 8 & Was appropriate statistical analysis used? & $\sqrt{ }(28)$ & & & \\
\hline
\end{tabular}

Critical appraisal

Critical appraisal for cross sectional studies was done based on Joanna Briggs Institute (JBI) check list. The appraisal showed that strategies to deal with confounding factors should be better addressed.

as 1) studies that examined the prevalence of depressive symptoms and their effect on patient outcomes, 2) studies that examined the prevalence of dietary non adherence and their effect on patient outcomes, and 3) studies that focused on the relationship between depressive symptoms and dietary non adherence. Studies were excluded if the investigators included patients with major depressive disorders.

\section{Results}

Among 141 articles produced from the initial search 28 were included in the review. Eleven studies (39.3\%) reported on the prevalence of depressive symptoms or depression and its effect on patient outcomes for those with ESRD. Ten studies (35.7\%) focused on dietary adherence/non adherence in patients with ESRD and the remaining seven (25\%) articles examined the relationship

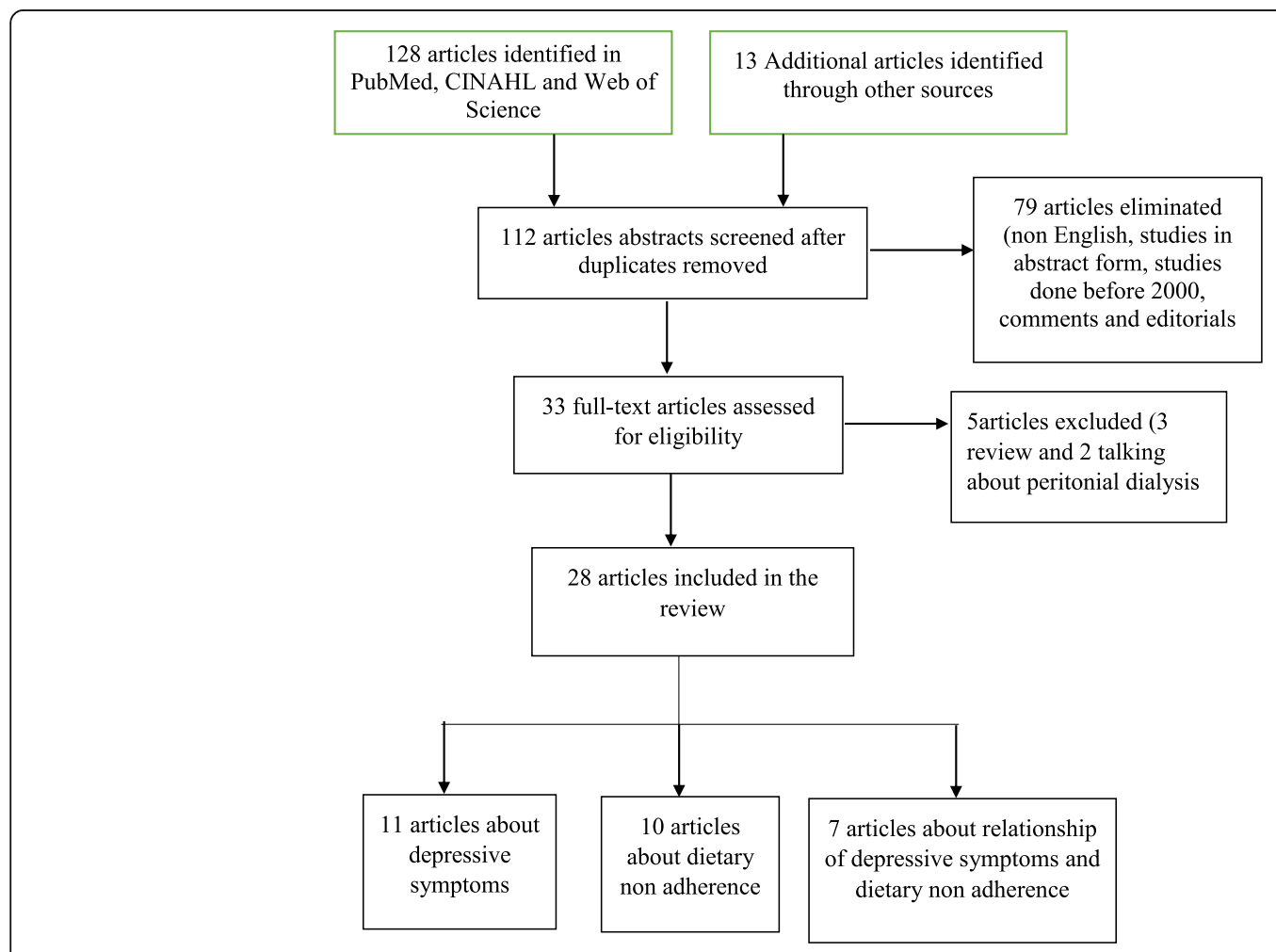

Fig. 1 Preferred reporting items for systematic reviews and meta-analyses diagram showing the flow of information for this review 
between depressive symptoms and dietary non adherence in patients with ESRD receiving hemodialysis.

\section{Depressive symptoms}

Out of the eleven studies reporting on the prevalence of depressive symptoms in ESRD patients, nine (81.8\%) had a sample size greater than 100 patients. The prevalence of depressive symptoms measured by self-report instruments ranged from 6 to 83.5\% [18, 23-28]. Despite such discrepancies, depression was one of the most prevalent mental illnesses among hemodialysis patients [12, 18, 19].

Regarding factors associated with depressive symptoms, three $(27.3 \%)$ out of eleven studies established positive associations between depressive symptoms and increased morbidity and mortality in patients with ESRD $[4,25,29]$. In three other $(27.3 \%)$ studies, a significant negative correlation between depressive symptoms and quality of life was found [24, 25, 30]. In the remaining five (45.4\%) studies clinical variables such as urea, hemoglobin, creatinine and serum albumin were associated with depressive symptoms. Moreover, studies found a greater likelihood of depressive symptoms among those who were younger in age, un-employed or had decreased social support [4, 23, 27]. However, inconsistent results were found for age, as old age was a significant predictor of depression in other studies [28, 30].

\section{Dietary non-adherence}

The prevalence of dietary non adherence in ESRD patients having hemodialysis was estimated in ten (37\%) of the studies included in this review. These studies used a variety of screening tools including indirect measures such as patients' self-reports and direct measures such as predialysis serum levels of potassium, phosphate, and urea nitrogen. Estimates of dietary non adherence using selfreport measures ranged from 41.1-98.3\% [31-35]. Non adherence ranged from 5.5 to $18 \%$ for potassium intake and from 11.7 to $25.5 \%$ for phosphorus intake [36-38].

Demographic correlates of dietary non adherence in ESRD patients having hemodialysis demonstrated a wide range of variation. Among ten studies that assessed dietary non adherence four $(40 \%)$ reported younger patients were at higher-risk for non-adherence with increasing age significantly decreasing the level of non-adherence $[31,33,34,36]$. In two (20\%) studies, an association between the lack of social support (family support) and dietary non adherence was found [32, 34]. An association between smoking and dietary non adherence was reported in two $(20 \%)$ studies $(36,31)$. Others found a positive relationship between adherence and educational status in this population [33, 37]. Education about diet and fluid restrictions and dietary counselling increase patient motivation to change and comply with dietary recommendations which in turn may improve dietary compliance [37]. Likewise, research findings demonstrated that patients with ESRD were more likely to adhere to their dietary restrictions if they had more positive attitudes and higher levels of perceived behavioral control [39].

\section{Depressive symptoms and dietary non adherence}

Among 28 studies included in this systematic review, seven studies examined the relationship between depressive symptoms and dietary non adherence in patients with ESRD who were having hemodialysis therapy. Even though it is not clear whether depression may be the cause or the end result of malnutrition in chronic hemodialysis patients [20], studies reported a negative association between depressive symptoms/depression and dietary adherence $[18,21,40,41$,$] . A study also re-$ vealed a close association between depressive symptoms and malnutrition in this population, which may be sign of non-adherence [40]. However, a study done on Chinese hemodialysis patient relied on inter-dialytic weight gain confirmed no association between depressive symptoms and non-adherence [16].

\section{Discussions}

\section{Depressive symptoms}

Even though depression is the prevalent mental illness in this review, findings from each included study demonstrated discrepancy. The reason for the large variation in prevalence across studies may be due to the diverse populations' studied and different self-report instrument used to measure depression with no consistent cut point value employed in those studies. Similarly, the difficulty in defining depression has led to challenges in its measurement.

Most (72.7\%) of the studies assessed depressive symptoms using self-report instruments and only three (27.3\%) used both patient self-report and physician diagnosis. Among the latter, the prevalence of physiciandiagnosed depression was $13.9 \%$, which was approximately three times lower than the prevalence for patients using self-reported Center for Epidemiologic Studies Depression Scale (CES-D) score (43.0\%) [29]. Among those studies that applied patient self-report six (54.5\%) used the Beck depression inventory (BDI), and the remaining five studies utilized a number of other self-report measures of depressive symptoms.

The BDI is considered to be the most commonly used and standard instrument for assessing symptoms of depression and the prevalence and severity of depression $[41,42]$. However, the use of this scale in ESRD of patients is challenging due to the somatic manifestation, included in the score that may be complicated by symptoms from uremia [43]. It has been psychometrically tested and validated for ESRD patients [44]. Additionally, 
the measure has been found to correlate highly with the diagnostic criteria for depression, quality of life, functional status and survival over time [45]. A variety of other measures were used to assess depressive symptoms in ESRD patients receiving hemodialysis. One study employed the CES-D scale to determine the prevalence of depression in ESRD patients [24]. Even though there is a lack of studies on the validity of CES-D in this population, it has been validated against the Beck Depression Inventory and shown to have predictive power for clinical outcomes in patients with other diseases [46, 47].

Studies also used measures including the Hospital Anxiety and Depression Scale (HADS) and Geriatric Depression Scale (GDS) $[23,30]$. The application of diverse instruments in these studies delivered challenges for researchers to compare findings across studies and populations, which may influence global conclusions about the prevalence of depressive symptoms in ESRD patients.

Inconsistent result was found about factors affecting depressive symptoms. This may be related to small sample sizes, patient characteristics [24, 27] and diverse countries with different cultures represented across those studies [16]. Generally, both the prevalence and factors associated with depressive symptoms showed inconsistency in these studies. In addition, the variability of screening methods for depressive symptoms made the comparison between studies challenging.

\section{Dietary non adherence}

The prevalence of dietary non-adherence is again inconsistence. Inconsistent prevalence-rates across these studies may be the result of biological measures being affected by many factors including residual renal function, dialysis adequacy, time at which blood was obtained for the analysis between dialysis, acid-base balance, and adherence with medication [48]. Furthermore, the large variation in estimates using self-reported instruments was possibly caused by the lack of generally accepted and validated gold standard measure of adherence [39].

Six (60\%) out of the ten studies employed the Dialysis Diet and Fluid Non-Adherence Questionnaire (DDFQ) [31-35, 39] while two studies utilized selfreport measures other than DDFQ [36, 39]. The DDFQ was designed to measure non-adherence behavior with diet and fluid in ESRD patients having hemodialysis with established content validity in the last 14 days. Moreover, its validity could be supported by using biological measures including serum potassium, phosphorus, and BUN levels [39]. Concerning the internal consistency of DDFQ, a Cronbach's alpha of 0.81 was reported when the measure was used with patients receiving hemodialysis [31]. Studies demonstrated that DDFQ is weakly but positively correlated with biomedical indicators of adherence, such as interdialytic weight gain $[31,39]$ whereas another study revealed no significant correlations between any of the biochemical measures of dietary adherence and selfreported dietary adherence [39].

Overall, variables such as young age, social support, educational status, behavioral control and positive attitudes were identified as factors significantly associated with dietary non adherence in ESRD patients receiving hemodialysis. In general, studies demonstrated diverse results in both the prevalence of dietary non adherence and in its related risk factors.

\section{Depressive symptoms and dietary non adherence}

Although majority of the studies reported a negative association between depressive symptoms/depression and dietary adherence, there is still a report of no association. The inconsistent findings may be related to the use of different instruments, some studies used the Dialysis Diet and Fluid non adherence Questionnaire (DDFQ) self-reports measure [18] and others employed different biomarkers to assess dietary non adherence in these studies. For example, one study measured blood urea nitrogen (BUN), serum creatinine, potassium, and phosphate levels [49] whereas others assessed serum albumin and protein catabolic rate $[20,40,50]$ as indicators of dietary non adherence. Additional issues include: different characteristics of the study samples, the use of small and convenient sampling and inclusion of a wide range of countries with different cultures. Although, these issues make study comparison more difficult, most of these researchers concluded that having depressive symptoms was associated with increased dietary non adherence. However, without considering this issues and without uniformly applying standardized criteria, establishing a causal relationship between depressive symptoms and dietary non adherence remains difficult. Moreover, since all studies included in this review are cross-sectional, the lack of temporal ordering to test if depression leads to dietary non adherence or depression results from dietary non adherence is a weakness.

\section{Conclusions}

In conclusion, despite the variation in assessment tool applied, depressive symptoms and dietary non adherence were highly prevalent in patients with ESRD receiving hemodialysis therapy. Nearly all of the articles that examined the relationship between depressive symptoms and dietary non adherence showed significant associations. Therefore, it is possible to recommend that early diagnosis and treatment of depression and close monitoring of adherence behavior are especially important in ESRD patients to improve their quality of life. Moreover, it will be important to consider both pharmacological 
and non-pharmacological (e.g. social support) interventions to reduce depression in order to enhance adherence and improve survival rates. This review brought up a clear association between depressive symptoms and dietary non-adherence which enable health care providers, specifically, nurses working in nephrology unit and related areas to monitor and improve patients QOL by providing appropriate interventions. Since this review included cross sectional studies, a causal relationship between depressive symptoms and dietary non adherence among ESRD patients receiving hemodialysis cannot be determined at this time. Future research (experimental or cohort studies) using gold standard measures with established cut-points is needed to further define this relationship and explores appropriate interventions. Moreover, as this review included only quantitative studies and searched limited databases, some studies might not be included in the review.

\section{Abbreviations}

BDI: Beck depression inventory; BUN: Blood urea nitrogen; CES-D: Center for Epidemiologic Studies Depression Scale; DDFQ: Dialysis Diet and Fluid Nonadherence Questionnaire; ESRD: End Stage Renal Disease; GDS: Geriatric Depression Scale; HADS: Hospital Anxiety and Depression Scale

\section{Acknowledgements}

No

\section{Authors' contributions}

MHG performed literature search, reviewed literature, made the analysis and wrote the initial drafting of the manuscript. JF made critical revisions, suggestions and additions and participated in revising the manuscript. Both authors read and approved the final manuscript.

\section{Authors' information}

Mingote is Assistant Professor at the School of Nursing, College of Medicine and Health Sciences, University of Gondar, Ethiopia. She has a Bachelor of Science in Nursing (BSN) and MSN in Adult Health Nursing.

Jodi is Associate Professor at the Ohio State University, College of Nursing, Collumbus, Ohio. She has a Bachelor of Science in Nursing (BSN), a MSN in Nursing and a PhD in Public Health.

\section{Funding}

The review was not supported by any funding.

\section{Availability of data and materials}

All articles retained for this review were acquired via PubMed, CINHAL and Web of science and are available to the public. All data analyzed in the present study is included in the published article.

\section{Ethics approval and consent to participate}

Not applicable.

\section{Consent for publication}

Not applicable.

\section{Competing interests}

The authors declare that they have no competing interests.

\section{Author details}

'University of Gondar, College of Medicine and Health Sciences, School of Nursing, Gondar, Ethiopia. ${ }^{2}$ The Ohio State University, College of Nursing, Columbus, $\mathrm{OH}, \mathrm{USA}$.
Received: 4 July 2019 Accepted: 8 November 2019

Published online: 21 November 2019

\section{References}

1. Chironda G, Bhengu B. Contributing factors to non-adherence among chronic kidney disease (CKD) patients: a systematic review of literature. Med Clin Rev. 2016;2(4). https://doi.org/10.21767/2471-299X.1000038.

2. SuSeł J, Batycka-Baran A, Reich A, C. Szepietowski J. Uraemic pruritus markedly affects the quality of life and depressive symptoms in Haemodialysis patients with end-stage renal disease. Acta Derm Venereol. 2014:94:276-81. https://doi.org/10.2340/00015555-1749.

3. Abdelkader R, Anwar A, Masaadi R, Ibrahim M, Alrimawi I. Exploring the quality of life of Jordanian children and adolescents with end stage renal disease receiving hemodialysis. Eur Sci J. 2016;12(35):17 10.19044.

4. Lopes A, Bragg J, Young E, Goodkin D, Mapes D, Combe C, et al. Depression as a predictor of mortality and hospitalization among hemodialysis patients in the United States and Europe. Kidney Int. 2002;62:199-207.42.

5. Joshi VD. Quality of life in end stage renal disease patients. World I Nephrol. 2014:3(4):308-16. https://doi.org/10.5527/wjn.v3.i4.308.

6. Pezeshki LM, Rostami Z. Contributing factors in health-related quality of life assessment of ESRD patients: a single center study. Int I Nephrol Urol. 2009; 1(2):129-36

7. Yong DS, Kwok AO, Wong DM, Suen MH, Chen WT, Tse DM. Symptom burden and quality of life in end-stage renal disease: a study of 179 patients on dialysis and palliative care. Palliat Med. 2009;23(2):111-9. https://doi.org/ 10.1177/0269216308101099.

8. García-Llana H, Remor E, Selgas R. Adherence to treatment, emotional state and quality of life in patients with end-stage renal disease undergoing dialysis. Psicothema. 2013;25(1):79-86. https://doi.org/10.7334/ psicothema2012.96.

9. Victoria A, Evangelos F, Sofia Z. Family support, social and demographic correlations of non-adherence among hemodialysis patients. Am J Nurs Sci. 2015;4(2-1):60-5. https://doi.org/10.11648/j.ajns.s.2015040201.21.

10. Sanavia $S$, Afshar R. Depression in patients undergoing conventional maintenance hemodialysis: the disease effects on dialysis adequacy. Dial Traspl. 2012;33(1):13-6. https://doi.org/10.1016/j.dialis.2011.06.006.

11. Yusop NB, Yoke MC, Shariff ZM, Beng HC. Factors associated with quality of life among hemodialysis patients in Malaysia. PLoS One. 2013;8(12):e84152. https://doi.org/10.1371/journal.pone.0084152.

12. Finnegan-John J, Thomas VJ. The psychosocial experience of patients with end-stage renal disease and its impact on quality of life: findings from a needs assessment to shape a service. ISRN Nephrol. 2012;2013:308986. https://doi.org/10.5402/2013/308986.

13. Spiegel BMR, Melmed G, Robbins S, Esrailian E. Biomarkers and healthrelated quality of life in end-stage renal disease: a systematic review. Clin J Am Soc Nephrol. 2008;3:1759-68. https://doi.org/10.2215/CJN.00820208.

14. Chau KF, Chak WL, Wong MK, Choi KS, et al. Rehabilitation of patients with end-stage renal disease. Medical Section. 2003;8(2).

15. Kimmel P, Varala M, Peterson R, Weihs $K$, Simmens $S$, Alleyne $S$, et al. Interdialytic weight gain and survival in hemodialysis patients: effects of duration of ESRD and diabetes mellitus. Kidney Int. 2000;57:1141-51.

16. Pang S, Ip W, Chang A. Psychosocial correlates of fluid compliance among Chinese hemodialysis patients. J Adv Nurs. 2001;35(5):691-8.

17. Denhaerynck K, Manhaeve D, Dobbels F, Garzoni D, Notle C, Geest S. Prevalence and consequences of non adherence to hemodialysis regimens. Am J Crit Care. 2007:16(3):222-35.

18. Khalil AA, Frazier SK, Lennie TA, Sawaya BP. Depressive symptoms and dietary adherence in patients with end-stage renal disease. J Ren Care. 2011;37(1):30-9.

19. Wang LJ, Chen CK. In: Polenakovic M, editor. ISBN: 978-953-51-0630-2, InTech.; Available from: http://www.intechopen.com/books/renal-failure-thefacts/the-psychological-impact-ofhemodialysis-on-patients-with-chronicrenal-failure The psychological impact of hemodialysis on patients with chronic renal failure, renal failure - the facts; 2012.

20. Koo JR, Yoon JW, Kim SG, Lee YK, Oh KH, Kim GH, et al. Association of depression with malnutrition in chronic hemodialysis patients. Am J Kidney Dis. 2003;41:1037-42.

21. Lee SK, Lee TB, Kim DH, Koo JR, Kim YK, Son BK. The effects of antidepressant treatment on serum cytokines and nutritional status in hemodialysis patients. J Korean Med Sci. 2004;19:384-9. 
22. Cukor D, Friedman S. Towards the psychosocial treatment of depressed patients on dialysis. Internet J Nephrol. 2004;2(2):3

23. Amado L, Poveda V, Ferreira R, Ferreira N, Miranda V, Teixeira $L$, et al. Depression in late-life patients with end-stage renal disease under onlineHaemodiafiltration is associated with low social support, muscular mass and creatinine serum levels. J Clin Nephrol Ren Care. 2016;2:007.

24. Santos PR. Depression and quality of life of hemodialysis patients living in a poor region of Brazil. Rev Bras Psiquiatr. 2011;33:332-7.

25. Ossareh S, Tabrizian S, Zebarjadi M, Joodat RS. Prevalence of depression in maintenance hemodialysis patients and its correlation with adherence to medications. Iran J Kidney Dis. 2014;8(6):467-74.

26. Makara-Studzińska M, Koślak A. Depression symptoms among patients with end stage renal disease and among primary health care patients. Arch Psychiatry Psychother. 2011;3:5-10.

27. Hakami H, Abdelsalam MS, Rashwan M, Althaf MM, Saleem N, et al. Depression in end-stage renal disease patients on hemodialysis: a single center experience in Saudi Arabia. Urol Nephrol Open Access. 2016;3(6):00103.

28. Jeon HJ, Park HC, Park Jl, Lee JP, et al. The effect of depression and healthrelated quality of life on the outcome of hemodialysis patients. Kidney Res Clin Pract. 2012;31:54-61

29. Lopes A, Albert J, Young E, Sayayathum S, Pisoni R, Andreucci V, et al. Screening for depression in hemodialysis patients: associations with diagnosis, treatment, and outcomes in the DOPPS. Kidney Int. 2004;66:2047-53.

30. Turkistani I, Nuqali A, Badawi M, Taibah O, Alserihy O, Morad M, et al. The prevalence of anxiety and depression among end-stage renal disease patients on hemodialysis in Saudi Arabia. Ren Fail. 2014;36(10):1510-5. https://doi.org/10.3109/0886022X.2014.949761.

31. Kugler C, Valminck H, Haverich A, Maes B. Non adherence with diet and fluid restrictions among adults having hemodialysis. J Nurs Scholarsh. 2005; 37(1):25-9.

32. Kara B, Caglar K, Kilic S. Non adherence with diet and fluid restrictions and perceived social support in patients receiving hemodialysis. J Nurs Scholarsh. 2007;39(3):243-8

33. Khalil AA, Darawad M, AIGamal E, Hamdan-Mansour AM, Abed MA. Predictors of dietary and fluid non-adherence in Jordanian patients with end-stage renal disease receiving hemodialysis: a cross-sectional study. J Clin Nurs. 2012;22:127-36. https://doi.org/10.1111/j.1365-2702.2012.04117.

34. Ahrari S, Moshki M, Bahrami M. The relationship between social support and adherence of dietary and fluids restrictions among hemodialysis patients in Iran. J Caring Sci. 2014;3(1):11-9. https://doi.org/10.5681/jcs.2014.002.

35. Efe D, Kocaöz S. Adherence to diet and fluid restriction of individuals on hemodialysis treatment and affecting factors in Turkey. Jpn J Nurs Sci. 2015; 12:113-23. https://doi.org/10.1111/jjns.12055.

36. Kutner N, Zhang R, McClellan W, Cole S. Psychosocial predictors of noncompliance in hemodialysis and peritoneal dialysis patients. Nephrol Dial Transplant. 2002;17:93-9.

37. Rambod M, Peyravi H, Shokrpour N, Sareban MT. Dietary and fluid adherence in Iranian hemodialysis patients. Health Care Manag. 2010;29(4): 359-64. https://doi.org/10.1097/HCM.0b013e3181fa0691.

38. Hecking E, Bragg-Gresham JL, Rayner HC, et al. Hemodialysis prescription, adherence and nutritional indicators in five European countries: results from the dialysis outcomes and practice patterns study (DOPPS). Nephrol Dial Transplant. 2004;19:100-7. https://doi.org/10.1093/ndt/gfg418.

39. Vlaminck H, Maes B, Jacobs A, Reyntjens S, Evers G. The dialysis diet and fluid non-adherence questionnaire: validity testing of a self-report instrument for clinical practice. J Clin Nurs. 2001;10:707-15.

40. Ekramzadeh M, Mazloom Z, Jafari P, Ayatollahi M, Sagheb MM. Major barriers responsible for malnutrition in hemodialysis patients: challenges to optimal nutrition. Nephro Urol Mon. 2014;6(6):e23158. https://doi.org/10. 5812/numonthly.23158.

41. Grothe KB, Dutton GR, Bodenlos J, Ancona M, Jones GN, Brantley PJ. Validation of the Beck depression inventory - II in a low-income African American sample of medical outpatients. Am Psychol Assoc. 2005;17(1):110 4. https://doi.org/10.1037/1040-3590.17.1.110.

42. Steer RA, Cavalieri TA, Leonard DM, Beck AT. Use of the Beck depression inventory for primary care to screen for major depression disorders. Gen Hosp Psychiatry. 1999;21:106-11.

43. Beck A, Steer RA, Garbin MG. Psychometric properties of the Beck depression inventory: twenty-five years of evaluation. Clin Psychol Rev. 1988;8:77-100.

44. Chilcot J, Norton S, Wellsted D, Almond M, Davenport A, Farrington K. A confirmatory factor analysis of the Beck depression inventory-II in end stage renal disease patients. J Psychosom Res. 2011;71:148-53. https://doi.org/10 1016/j.jpsychores.2011.02.006

45. Kimmel P, Wehs K, Peterson R. Survival in hemodialysis patients: the role of depression. J Am Soc Nephrol. 1993:3:12-27.

46. Kojima M, Furukawa TA, Takahashi $\mathrm{H}$, et al. Cross-cultural validation of the Beck depression inventory-II in Japan. Psychiatry Res. 2002;110:291-9.

47. Wassertheil-Smoller S, Shumaker S, Ockene J, et al. Depression and cardiovascular sequelae in postmenopausal women. The Women's health initiative (WHI). Arch Intern Med. 2004:164:289-98.

48. Dwyer J, Larvine B, Leung J, ARocco M, Burrowes J, Chumlea W, et al. Nutritional status affects quality of life in hemodialysis (HEMO) study patients at baseline. J Ren Nutr. 2002;12(4):213-23.

49. Fincham D, Kagee A, Moosa MR. Dietary and fluid adherence among hemodialysis patients attending public sector hospitals in the Western cape. S Afr J Clin Nutr. 2008:21(2):7-12.

50. Akman B, Uyar M, Afsar B, Sezer S, Ozdemir F. Adherence, depression and quality of life in patients on a renal transplantation waiting list. Transpl Int. 2007;5(48):1-6.

\section{Publisher's Note}

Springer Nature remains neutral with regard to jurisdictional claims in published maps and institutional affiliations.
Ready to submit your research? Choose BMC and benefit from:

- fast, convenient online submission

- thorough peer review by experienced researchers in your field

- rapid publication on acceptance

- support for research data, including large and complex data types

- gold Open Access which fosters wider collaboration and increased citations

- maximum visibility for your research: over $100 \mathrm{M}$ website views per year

At BMC, research is always in progress.

Learn more biomedcentral.com/submissions 